University of Michigan Medical Center, Ann Arbor, Michigan, and Aerospace Medical Laboratory, Wright Air Development Division, Dayton, Ohio

\title{
A COMPARATIVE STUDY OF CYTOARCHITECTONICS AND CHEMO. ARCHITECTONICS OF THE CEREBRAL CORTEX OF THE GUINEA PIG
}

\author{
By \\ Reinhard L. Friede \\ With 7 Figures in the Text \\ (Received May 13, 1960)
}

A previous investigation of the histochemical distribution of succinic dehydrogenase in the brain of the guinea pig showed considerable gradations of intensity and distribution of enzymic activity among the areas of the cerebral cortex (Friede 1960). These findings stimulated an interest in a more detailed comparison of the cortical cytoarchitectonics (Rose 1912, KRIEG 1946) with chemoarchitectonics. Such an investigation was made possible by removing the histochemical stain from the tissue and restaining the sections with a cell stain. This technique was used with success for the demonstration of enzymatic changes during axonal reaction of nerve cells (FrIEde 1959 b).

\section{Material and Methods}

Succinic dehydrogenase was demonstrated in frozen sections from unfixed tissue, 60 micra thick. The tissue had to be cut at a temperature of -3 to $-1^{0} \mathrm{C}$ if Tetrazolpurpur was used, since controlled temperature during cutting prevents the formation of coarse crystals in the tissue (FRIEDE 1958). The sections were transferred from the knife for 2 hours at $38^{\circ} \mathrm{C}$ into the incubation medium which contained equal parts of: sodium succinate $1 \% ; 0.1 \mathrm{M}$ phosphate buffer; $\mathrm{p}_{\mathrm{H}} 7,8$; and Tetrazolpurpur $0,25 \%$. The incubation was terminated by pouring the contents of the incubation containers (small weighing bottles) into $10 \%$ formalin. Sections were mounted with glycerin gelatin. Nitro BT ( $1 \mathrm{mg} / \mathrm{ml}$, NACHLAS and coworkers 1957) proved more advantageous than Tetrazolpurpur because it required a less rigid control of the eutting temperature and was more sensitive. The restaining technique deseribed below, however, required Tetrazolpurpur because of poor solubility of the formazan from Nitro BT. Otherwise both Tetrazolium derivatives showed identical results. This technique for SDA is so reliable that it permits photometrical measurements (FrIEDE 1960).

Restaining technique: Photomicrographs were taken from sections stained for succinic dehydrogenase; the sections then were removed from the slides, dehydrated in alcohols and transferred into alcohol-ether at $38^{\circ} \mathrm{C}$ which dissolved the formazan within about 2 days. The bleached sections were transferred through alcohols back into water and stained with EINARSON's chromalum-gallocyanin; after staining, they were dehydrated again and mounted with balsam. Photographs were taken from the fields from which the enzyme activity was recorded. An effort was made to obtain exactly identical fields of the histochemical reaction and the cell stain. The pictures were adjusted one upon another on an illuminated screen so that landmarks in various parts of the sections were centered upon each other. It is possible, therefore, to obtain a cell-to-cell account of the enzyme localization.

\section{Results}

The functional significance of the gradations of succinc dehydrogenase are better understood by comparison with the findings in a recent comparative histochemical investigation of the brain stem of the cat in which measurements 
of SDA and capillarization were proportional to each other in 64 representative nuclei. Moreover SDA, cytochrome oxidase, TPN and DPN diaphorase showed a close similarity of their histochemical patterns. The pattern of SDA, therefore, can be used as a parameter of the general oxidative metabolic activity of a given region, which is intimately linked to function.

A detailed description of the histochemical distribution of succinc dehydrogenase activity (SDA) in the individual cortical areas was previously published. The following provides an abstract of the general chemoarchitectonics of the isocortex for orientation.

SDA in the first or molecular layer is diffusely distributed in the neuropil ${ }^{1}$; it is stronger in the superficial part of the layer than in its deep part. The SDA of the molecular layer varies little among the areas of the isocortex.

The border between the first and the second layer is indicated by an increase of SDA in the latter. The second, third, and fourth layers histochemically are not demarcated from each other and form one homogeneous band which is termed "upper cellular layers" in the following. These layers form a zone of diffuse activity in the neuropil in which very few pericarya are discernible. The pericarya of the majority of the cells contain less SDA than the surrounding neuropil; they are not discernible from the neuropil even in thinner sections or if a shorter incubation period is used. The SDA of the upper cellular layers varies considerably among the cortical areas; it is lowest in the insular and lower temporal cortex, somewhat higher in the precentral and the parietal cortex and is highest in the postcentral, the occipital and the auditory cortex. These gradations have been established densitometrically (Table).

The fifth and sixth layers are sharply demarcated from the upper cellular layers and, in the following, are termed "deep cellular layers". Their histochemical pattern differs from that of the upper cellular layers: the SDA in the pericarya prevails over the mild or weak SDA in the neuropil. The nerve cells of the fifth layer usually show a stronger SDA than those of the sixth layer and are better discernible from the neuropil. The enzymic activity of the deep cellular layers varies little among areas of the isocortex but the fifth layer is very thick in the frontal cortex.

Many of the chemoarchitectonic differences among cytoarchitectonic areas of the isocortex result from gradations of enzymic activity in the neuropil which behaves like an individual tissue structure. There is no sharp boundary of the neuro pil of individual cortical areas, so that most of the transitions are gradual and do not permit sharp separation of areas as by drawing a line.

The allocortical areas show a greater variability of patterns but all of them show stronger SDA in the molecular layer than is found in the isocortex. Particularly the pyriforme cortex (area 51) shows stronger SDA in its molecular layer than in any of its deeper layers. Other regions show specific patterns such as the trilaminate pattern of the retrolimbic cortex (area 29) or the specific chemoarchitectonics of the hippocampus and the bulbus olfactorius but these patterns are too diversified to be described in detail in this article.

1 The term neuropil is used to define the diffusely distributed enzyme activity outside of the pericarya; delicate dendrite ramifications obviously bear most of the enzymic activity found in the neuropil. For a more detailed discussion of the term neuropil see FrIEDT (1960). 
Table. Mean values of densitometric measurements of succinic dehydrogenase activity in various cortical areas, expressed as a percentage of the intensity measured in the putamen.

(Friede, J. Neurochem., 5,158)

\begin{tabular}{|c|c|c|c|c|c|c|}
\hline & \multicolumn{4}{|c|}{ Cortical layers } & \multirow{3}{*}{$\begin{array}{l}\text { Boundary } \\
\text { of cortex } \\
\text { and white } \\
\text { matter }\end{array}$} & \multirow{3}{*}{$\begin{array}{l}\text { White } \\
\text { matter }\end{array}$} \\
\hline & \multirow{2}{*}{$\begin{array}{l}\text { Molecular } \\
\text { layer } 1\end{array}$} & \multirow{2}{*}{$\begin{array}{l}\text { Upper } \\
\text { cellular } \\
\text { layer } 2 \\
\text { to } 4\end{array}$} & \multicolumn{2}{|c|}{ Deep cellular layers } & & \\
\hline & & & layer 5 & layer 6 & & \\
\hline Regio frontalis & 32 & 50 & 47 & 31 & not sharp & 10 \\
\hline $\begin{array}{l}\text { Regio postcentralis } \\
\text { area } 1-3-5\end{array}$ & 35 & 104 & 53 & 34 & sharp & 10 \\
\hline Auditory area 41 & & 97 & & & sharp & \\
\hline $\begin{array}{l}\text { Regio parietalis } \\
\text { area } 7\end{array}$ & 36 & 60 & $\begin{array}{l}43-50-43 \\
\text { sublaminae }\end{array}$ & 27 & scharp & 10 \\
\hline $\begin{array}{l}\text { Regio occipitalis } \\
\text { area } 17 \text { and } 18\end{array}$ & 35 & 93 & $\begin{array}{c}60-52 \\
\text { sublaminae }\end{array}$ & 36 & sharp & 10 \\
\hline $\begin{array}{l}\text { Inferior temporal } \\
\text { and insular cortex }\end{array}$ & 35 & 46 & 37 & 33 & sharp & \\
\hline $\begin{array}{l}\text { Area parorbitalis } \\
\text { area } 8\end{array}$ & 50 & 66 & 35 & 34 & not sharp & \\
\hline $\begin{array}{l}\text { Regio cingularis } \\
\text { area } 23\end{array}$ & & \multicolumn{3}{|c|}{$\begin{array}{c}80 \quad 47 \\
\stackrel{\text { gradual transition of the }}{\text { cellular layers } \rightarrow}\end{array}$} & sharp & \\
\hline $\begin{array}{l}\text { Area retrolimbica } \\
\text { area } 29\end{array}$ & $\begin{array}{cc}71 & 47 \\
\text { (upper) } & \text { (lower) } \\
\end{array}$ & 75 & $\begin{array}{l}4561 \\
\text { ourth) }\end{array}$ & 37 & not sharp & \\
\hline $\begin{array}{l}\text { Area parasubicularis } \\
\text { area } 49\end{array}$ & & $\leftarrow \operatorname{mer}$ & $\begin{array}{l}125 \\
\text { ed second to }\end{array}$ & $\begin{array}{c}\mathbf{5 1} \\
\text { ayer } \rightarrow\end{array}$ & not sharp & \\
\hline $\begin{array}{l}\text { Area prepiriformis } \\
\text { area } 51\end{array}$ & 87 & $\leftarrow$ mer & $\begin{array}{c}43 \\
\text { red cellular la }\end{array}$ & rers $\rightarrow$ & not sharp & \\
\hline $\begin{array}{l}\text { Tuber olfactorius } \\
\text { area } 51\end{array}$ & 71 & $\leftarrow$ mer & $\begin{array}{c}32 \\
\text { eed cellular la }\end{array}$ & yers $\rightarrow$ & $\begin{array}{l}\text { transition } \\
\text { into nucl. } \\
\text { amygdalae }\end{array}$ & \\
\hline Subiculum & $\begin{array}{c}23 \\
\text { fiber lay }\end{array}$ & $\leftarrow$ & $\begin{array}{l}75 \\
\text { rged cellulo }\end{array}$ & yers $\rightarrow$ & sharp & 11 \\
\hline
\end{tabular}

In the following, the results of a comparison of cytoarchitectonics and chemoarchitectonics of several representative cortical areas are described. It must be emphasized that the accompanying sets of pictures demonstrate exactly identical fields.

\section{Postcentral cortex (Figs. 1 and 2)}

The postcentral cortex of the guinea pig (and the rat) is characterized by a segmentation of the neuropil of the upper cellular layers (particularly the third and fourth layers), which is specific for this region. The dense cell population of the upper cellular layers is not discernible from the diffusely distributed SDA in the neuropil and neither is the dense cell lamina in the superficial part of the second layer reflected by enzymic distribution. The segmentation of the third and fourth layers is found only in the postcentral cortex but not in the auditory or the visual cortex which otherwise are very similar.

If restained sections are searched for a cytological pendant to this segmentation, a consistent inverse relationship is found between cell density and enzymic activity. 
The zones of very strong SDA are identical with areas with fewer cells; the zones of weak SDA between them show a dense packing of pericarya (Figs. 1

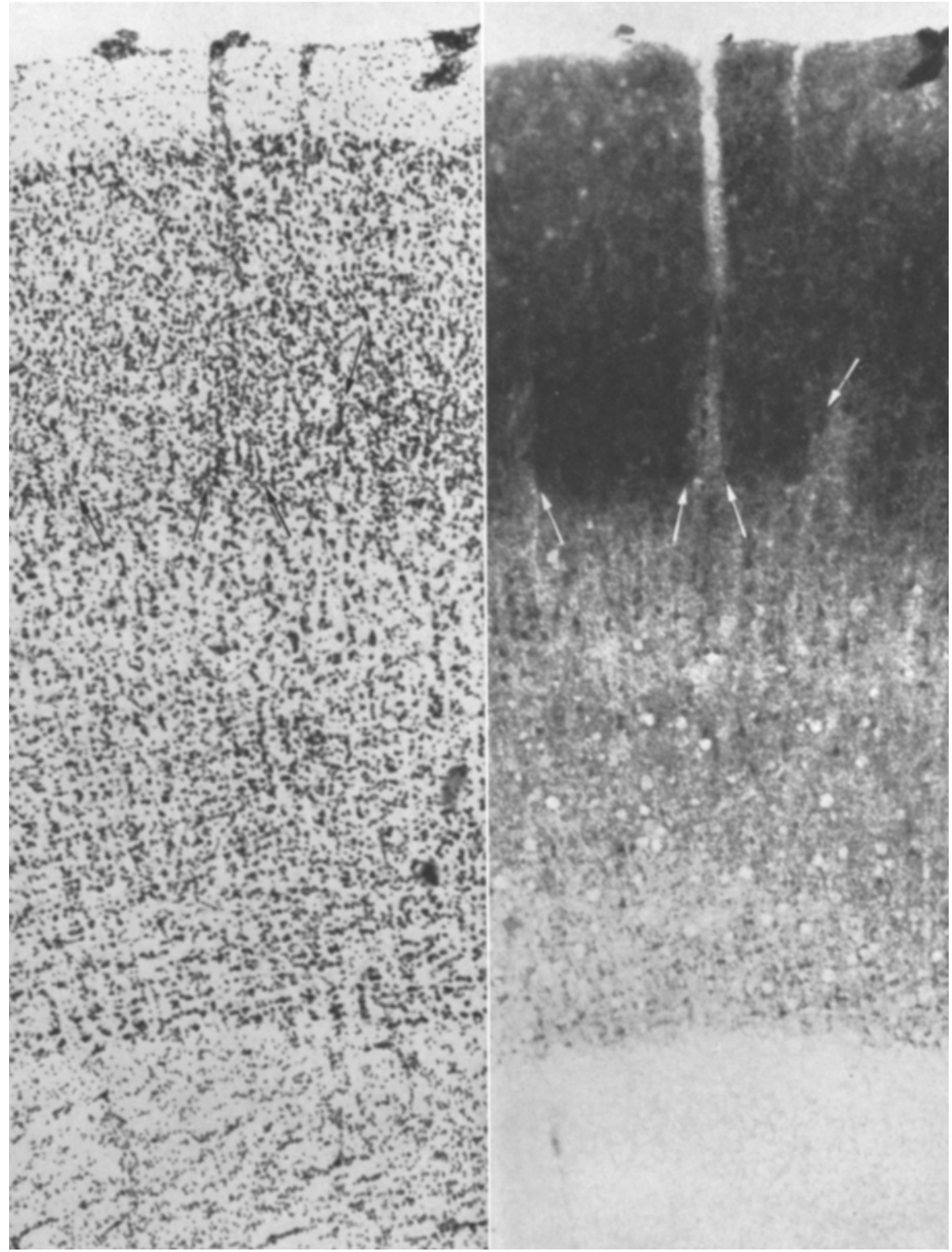

Fig. 1. Cytoarchitectonics and chemoarchitectonics of the postcentral region of the guinea pig; right and left picture show exactly identical fields. The arrows indicate that the histochemical segmentation of the third and fourth layers is reflected by inverse changes of the cell density

and 2). This inverse gradient is interpreted by comparison with the cytological distribution of SDA in the cerebellar granular cells. The pericarya of these cells contain little SDA while their synaptic glomerula cerebellaria show strong SDA (FRIEDE 1960) due to a shifting of metabolic activity from the pericaryon 
into the terminal ramifications of dendrites. An identical shift is characteristic for the fourth layer of the cerebral cortex, where the aggregations of pericarya

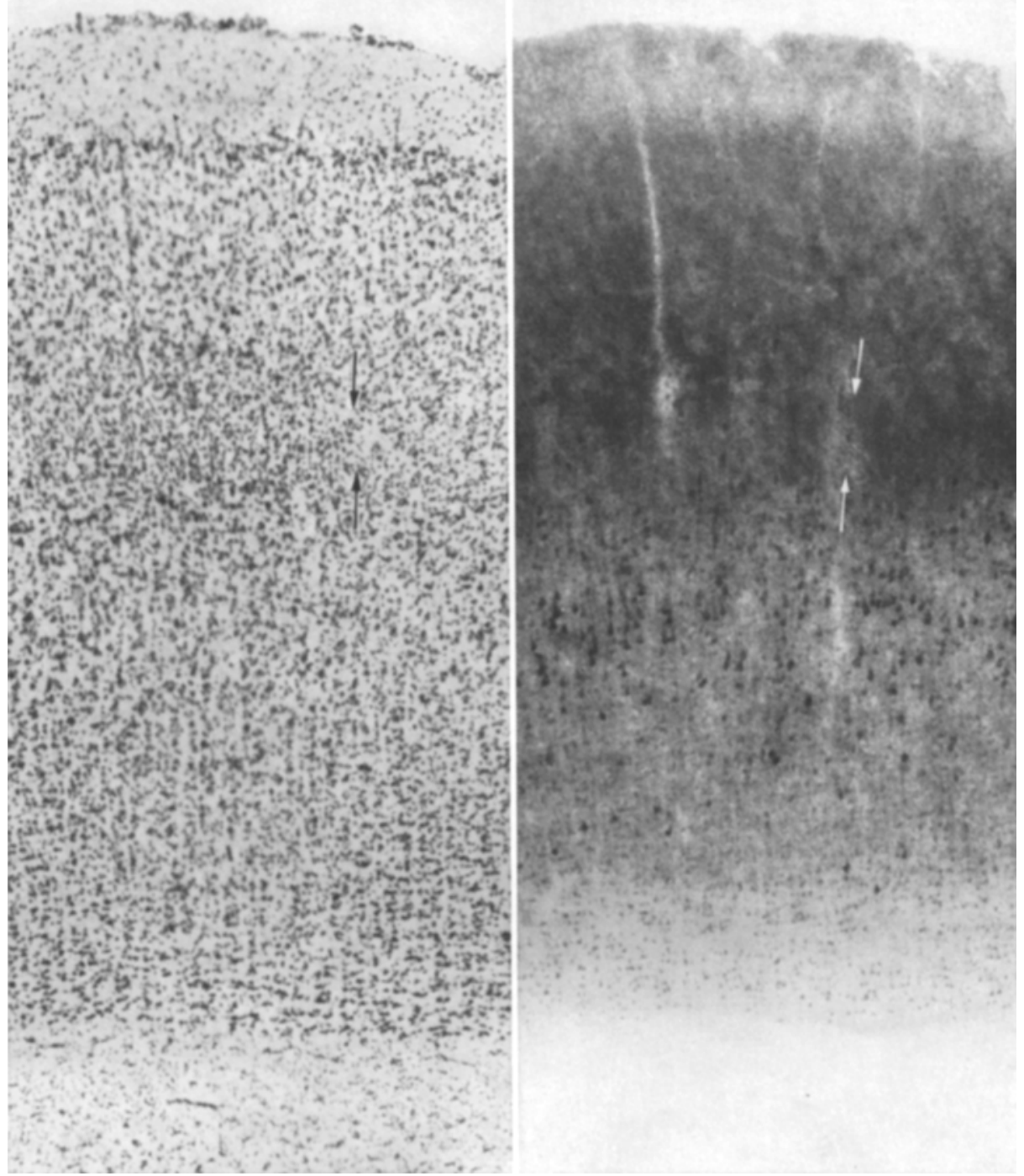

Fig. 2. Transition zone between postcentral and parietal cortex; note the inverse relationship between enzymic activity and cell density in the right and left side of the pictures as indicated by arrows

show less SDA than the zones of neuropil with rich dendrite ramifications. Nerve cells with very little SDA in their pericarya were frequently found in the upper cortical layers in a previous investigation studying isolated cells (FrIEDE 1960).

The shifting of SDA into the dendrites explains the difficulties which one encounters in delineating histochemically the fourth layer. The deep part of the fourth layer is very rich in pericarya and thus shows weak SDA; it is barely discernible, therefore, from the fifth layer which is characterized by mild SDA in its neuropil. 
The majority of the large pyramidal cells of the fifth layer show strong SDA in their pericarya which contrasts with the weak SDA in the intervening neuropil.

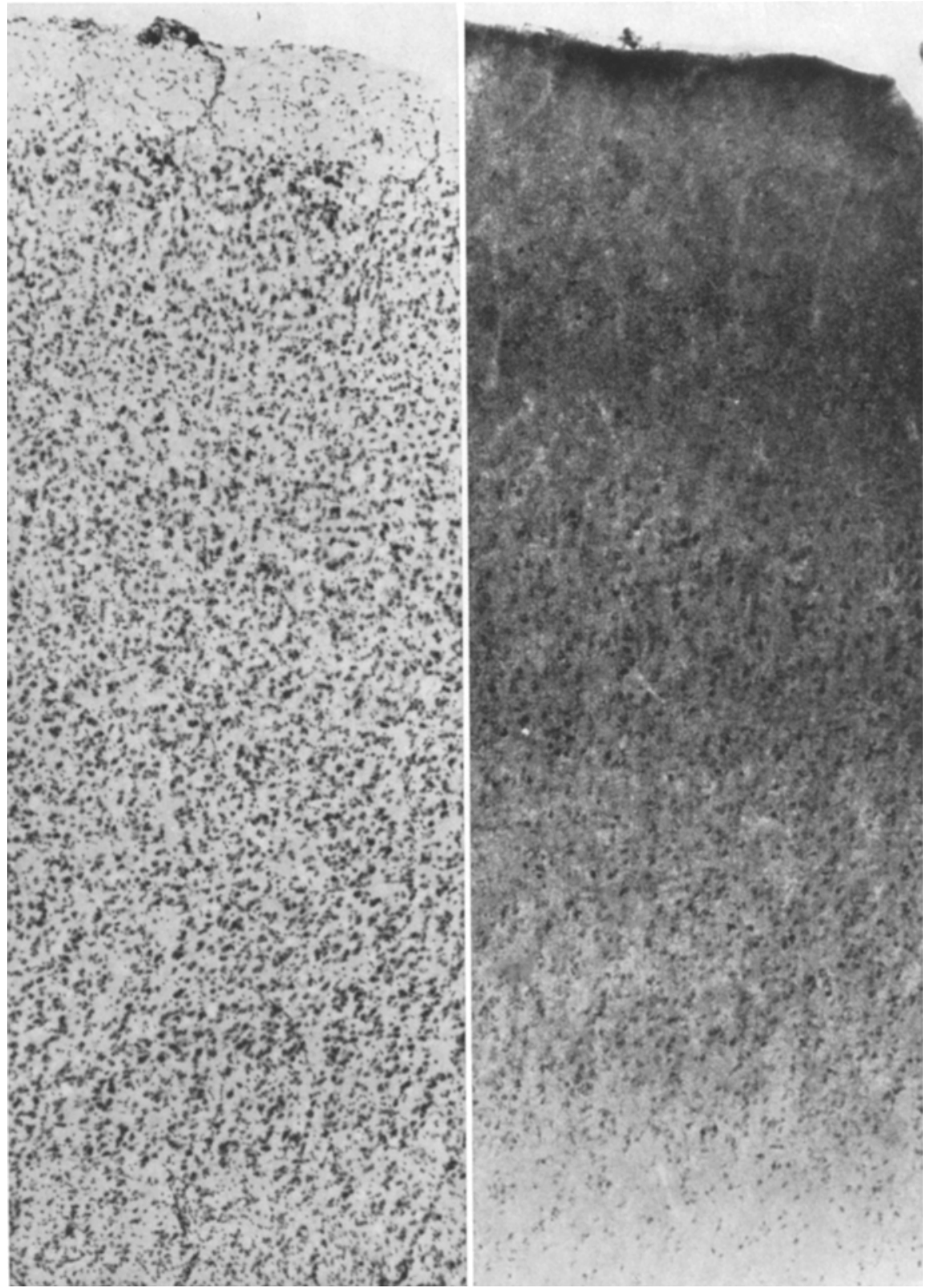

Fig. 3. Precentral cortex (cf. text)

The cells of the sixth layer show less SDA than those of the fifth layer; there are also gradations among individual cells. 
Although the density of glial cells in the white matter exceeds that in the molecular layer, SDA is almost absent in white matter but is mild in the molecular

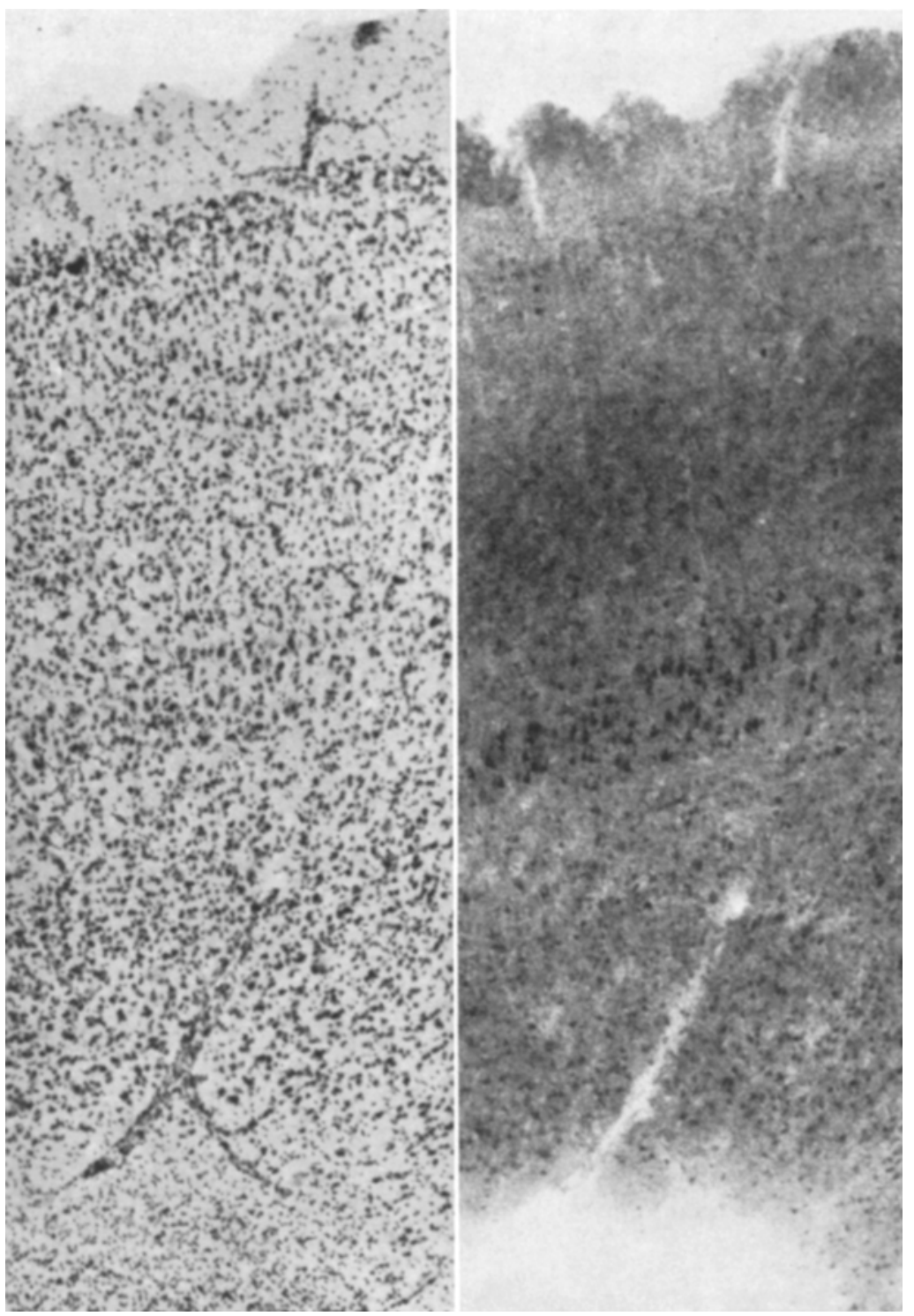

Fig. 4. Lower temporal cortex; note the prevalence of enzymic activity in the large pyramidal cells of the fifth layer which is typical for this region

layer; this indicates little contribution of glial cells to the enzymic activity of the neuropil.

Large blood vessels are discernible mainly by their lumen which produces an empty space in the tissue; capillaries are not discernible. Enzymic activity does not change with the distance from the vascular wall. 


\section{Precentral cortex (Fig. 3)}

The precentral cortex is discernible from the postcentral cortex by weaker SDA in the upper cellular layers and by the thicker fifth layer which shows widely scattered pyramidal cells. The cytological boundary of the first and second layer is scarcely reflected by SDA; most of the small pyramidal cells of the third layer are not discernible from the neuropil. The large pyramidal cells in the fifth layer can be identified by SDA.

\section{Insular and lower temporal cortex (Fig. 4)}

These areas show lowest SDA of the isocortex and are not discernible from each other. In spite of the weak reaction of the neuropil, only a few of the cells of the second and third layers are discernible. The majority of them contains less SDA, or SDA equal to that in the neuropil. It is typical for the temporal cortex that the pyramidal cells of the fifth layer show strongest SDA of all the cortical layers.

Two areas of the allocortex are described in the following because of their interesting enzyme patterns.

\section{Area retrosplenalis or area 29 (Fig. 5)}

The thick molecular layer shows a gradation of very strong SDA in its upper part and weak SDA in its deep part, but no cytological pendant to this gradation is found in the restained sections. The dense cell population of the adjacent upper layers seems, in this area, to be reflected by stronger SDA; however, zones of greatest cell density do not always coincide with zones of strongest enzyme activity and, comparing the layers among each other, there is absolutely no correlation of SDA and cell density.

\section{Area pyriformis or area 51 (Figs. 6 and 7)}

The area pyriformis shows a conspicuous prevalence of SDA in the molecular layer. The gradation of SDA within this layer is not clearly reflected by the glial density. The compact lamina of nerve cells bordering the molecular layer is almost indiscernible by SDA and can be localized only by the absence of SDA in the cell's nuclei. The deeper part of this lamina shows less cells but equal, if not stronger, SDA. The circular light spots in Fig. 6 are artefacts which appear in old sections; this section, for example, was photographed and restained after two and one-half years' storage, which demonstrates the stability and the absence of diffusion in the preparations.

The tuberculum olfactorius shows weakest SDA among the parts of the area 51; Fig. 7 shows its transition into the amygdaloid nucleus. The area with mild, diffusely distributed SDA in the top of the picture is the basal amygdaloid nucleus, delineated by a narrow fiber lamina without SDA. The region between this fiber lamina and the cortex represents the cortical amygdaloid nucleus (see Brodal 1957, JoHnson 1957), which histochemically lacks sharp boundaries with the pyriforme cortex. The large cell group in the left lower part of the picture is not discernible by SDA, contrary of the cells in the middle part of the 


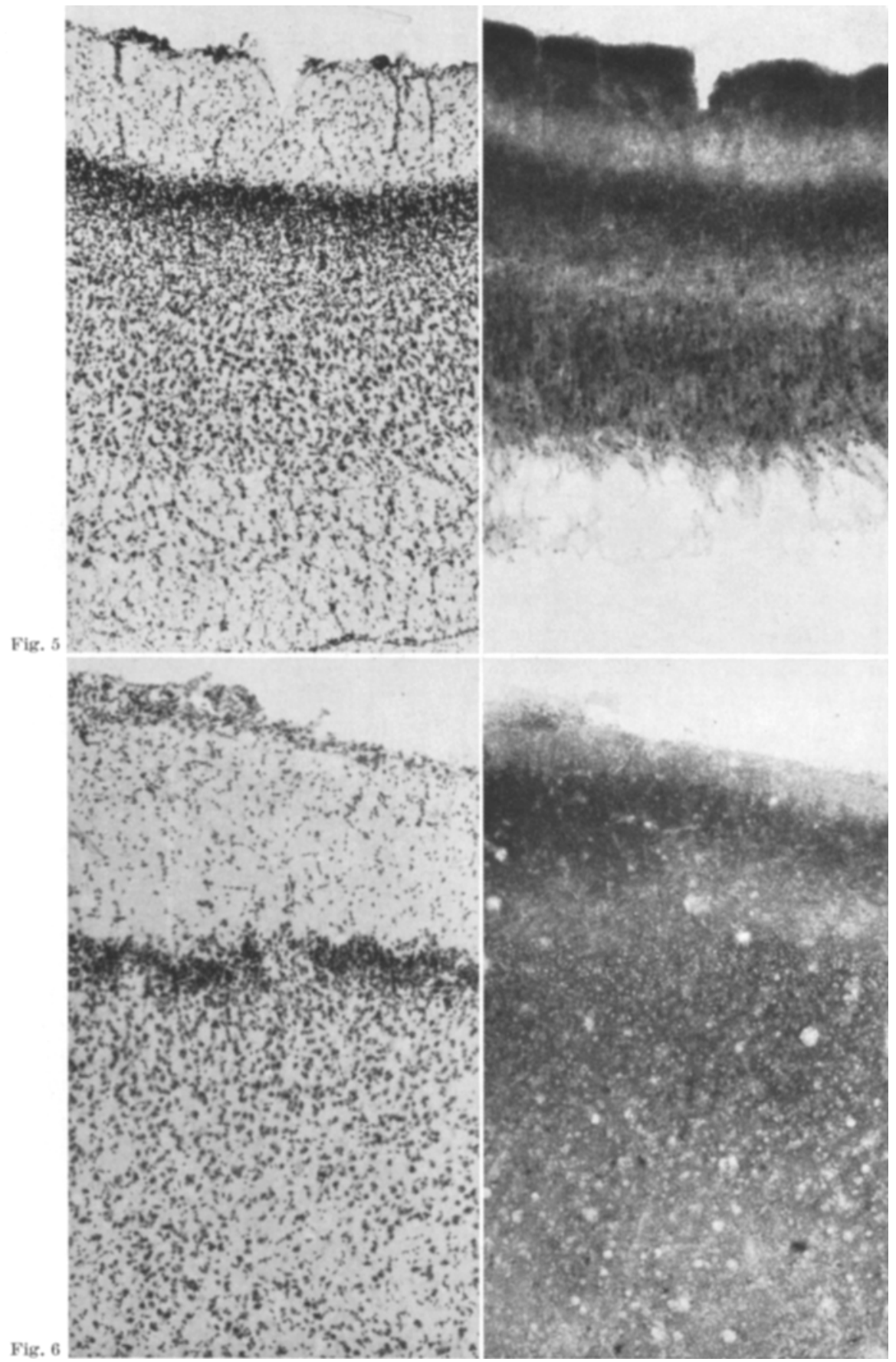

Fig. 5. Retrosplenial cortex (area 29) exhibiting its typical trilaminate pattern of enzyme distribution

Fig. 6. Pyriforme cortex (area 51). Enzymic activity prevails in the molecular layer and is relatively weak in the cell layers 


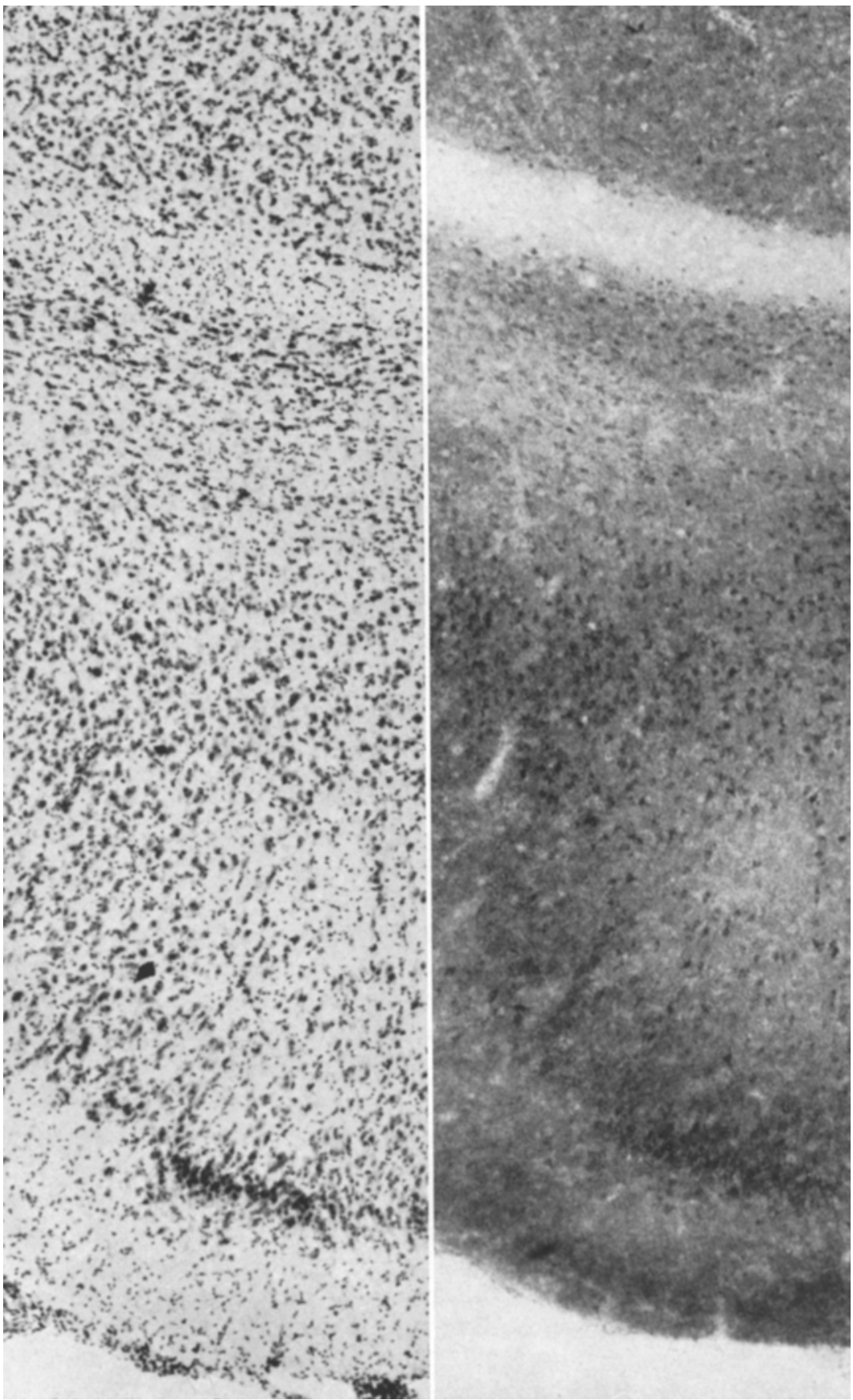

Fig. 7. Transition zone of the nucleus amygdalae (top) and the tuberculum acusticum; for identification of the individual structures see the text 
picture, which are readily identified in both photographs; this demonstrates the conspicuous individual variations of enzymic activity in the pericarya of certain regions.

\section{Discussion}

Considerable criticism of the principles of cytoarchitectonic cortical mapping arose following the investigation of LASHLEY and CLARK (1946), in which two investigators, working independently from each other with the same material, obtained different mappings of cortical areas. Therefore, the implications at which one arrives studying the chemical architectonics of the cerebral cortex shall be outlined shortly.

The main regions of the cerebral cortex are clearly discernible by differences in enzymic distribution. The transitions among these regions, however, are very gradual, even at places where the histochemical patterns are so different as between the pre- and the postcentral cortex. The sharp delineation of cortical areas by drawing a line is not supported histochemically. Most of the differences among areas are established by gradations of enzymic activity in the neuropil which has no sharp boundaries. The gradual changes in the neuropil also do not permit a more detailed areal subdivision of the cortex. There is, for example, a gradual increase of SDA in the upper cellular layers from the frontal pole to the precentral region which can be measured photometrically; however, there is nowhere a boundary along this line which would permit discernment of a frontopolar from a precentral area. Measurements of such gradations introduce a simple means to express the cortical architectonics quantitatively.

An observation which seems of basic importance for the understanding of the functional organization of the cortex is the shifting of enzymic activity in either dendrites or pericaryon. The fourth layer, for example, shows little enzymic activity in the pericarya but much in the neuropil, which, to a large part, is formed by dendrite ramifications. The fifth layer, on the other hand, shows enzymic activity prevailing in the pericarya. A complete and detailed mapping of SDA in the guinea pig's brain has shown that these cytological patterns are consistent and typical for certain nuclei (Friede 1959a). The cells maximal metabolic activity, therefore, can be shifted either towards the dendrites or towards the pericaryon and one may discern cells with dendritic and with somatic enzyme supply.

Which cytological parameters could reflect these intracellular biochemical patterns? It appears that the shifting of enzymic activity from the pericaryon into the neuropil is accompanied by a similar shift of cytoplasm as expressed by the size relationship of nucleus and pericaryon (Kern-Plasmarelation). Laminae in which enzymic activity prevails in the neuropil show nerve cells with little cytoplasm (granular cells) while laminae in which enzymic activity prevails in cell bodies show large pericarya. Measurements by BAUN (1951) give a relationship between nucleus and pericaryon of: $1.74,2.35,3.24$, in upper layers: deep layers: giant pyramidal cells of the horse's cortex.

The comparison of enzymic activity and glial cell density in the white matter and the molecular layer implies that glial cells contribute little of the enzymic activity of the neuropil. Glial cells, however, should not be disregarded completely, 
since cell counts in other regions implied some quantitative relationship of glial cell density and enzymic activity in the neuropil (FRIEDE 1960).

\section{Summary}

The histochemical distribution of succinic dehydrogenase in the guinea pig's cerebral cortex is compared with the cytoarchitectonics in restained sections. The cytoarchitectonic subdivision of the cortex is paralleled by gradations of enzymic activity which can be substantiated by densitometric measurements. The typical histochemical patterns of several representative regions are described. The histochemical pattern of succinic dehydrogenase may be regarded as a parameter of the general oxidative metabolic rate of a region.

A more detailed comparison of chemoarchitectonics and cytoarchitectonics shows that there is no correlation of cell density and enzymic activity since the nerve cell's maximal enzyme supply can be found either in the pericaryon or in the dendrites. These patterns of enzymic distribution are typical for the various laminae of the cortex.

\section{References}

BAUN, F.: Histologisch-statistische Untersuchungen am Großhirn des Pferdes mit besonderer Berücksichtigung der Mengen- und Artverhältnisse der Gliazellen zu den Ganglienzellen. Hannover Tierärztl. Hochschule, Diss. 21, 12 (1951).

Brodal, A.: The amgdaloid nucleus in the rat. J. comp. Neurol. 87, 1-16 (1947).

FRIEDE, R.: Improved technique for the histochemical demonstration of succinic dehydrogenase in brain tissue. J. Histochem. Cytochem. 6, 347-351 (1958 a).

FRIEDE, R.: Histochemical investigations on succinic dehydrogenase in the central nervous system. II. Atlas of the medulla oblongata of the guinea pig. J. Neurochem. 4, 111-123 (1959a).

FrIEDE, R.: Histochemical investigations on succinic dehydrogenase in the central nervous system. III. Atlas of the midbrain of the guinea pig, including pons and cerebellum. J. Neurochem. 4, 290-303 (1959 a).

Friede, R.: Transport of oxidative enzymes in nerve fibers; a histochemical investigation of the regenerative cycle in neurons. J. exp. Neurol. 1, 44l-466 (1959b).

FrIEde, R.: Histochemical investigations on succinic dehydrogenase in the central nervous system. IV. A histochemical mapping of the cerebral cortex of the guinea pig. J.Neurochem.5, 158-171 (1960).

Johnson, T. N.: Studies on the brain of the guinea pig. I. The nuclear pattern of certain basal telencephalic eenters. J. comp. Neurol. 107, 353-378 (1957).

KrIEG, W. J. S.: Connections of the cerebral cortex of the albino rat. A. Topography of the cortical areas. J. comp. Neurol. 84, 221-323 (1946).

Nachtas, M. M., K. C. Tsou, E. Souza, C. S. Cheng and A. M. Seligman: Cytochemical demonstration of succinic dehydrogenase by the use of a new p-nitrophenyl substituted ditetrazole. J. Histochem. Cytochem. 5, 420-436 (1957).

Rose, M.: Histologische Lokalisation der Großhirnrinde bei kleinen Säugetieren (Rodentia, Insectivora, Chiroptera). J. Psychol. Neurol. (Lpz.) 19, 389-479 (1912).

Dr. Reinhard L. Friede, Laboratory of Neuropathology, University of Michigan, Medical Center, Ann Arbor, (Michigan, USA) 